\title{
BMJ Open Barriers, facilitators, preferences and expectations of joint protection programmes for patients with hand arthritis: a cross-sectional survey
}

\author{
Pavlos Bobos (D) , 1,2,3 Joy MacDermid, , ${ }^{1,4,5,6}$ Christina Ziebart (D) , 5,6 \\ Eleni Boutsikari, ${ }^{7}$ Emily Lalone, ${ }^{6,8}$ Louis Ferreira, ${ }^{6,8}$ Ruby Grewal ${ }^{6}$
}

To cite: Bobos P, MacDermid J, Ziebart C, et al. Barriers, facilitators, preferences and expectations of joint protection programmes for patients with hand arthritis: a crosssectional survey. BMJ Open 2021;11:e041935. doi:10.1136/ bmjopen-2020-041935

- Prepublication history and additional materials for this paper is available online. To view these files, please visit the journal online (http://dx.doi. org/10.1136/bmjopen-2020041935).

Received 21 June 2020 Revised 06 January 2021 Accepted 13 January 2021

Check for updates

(c) Author(s) (or their employer(s)) 2021. Re-use permitted under CC BY-NC. No commercial re-use. See rights and permissions. Published by BMJ.

For numbered affiliations see end of article.

Correspondence to Dr Pavlos Bobos, Applied Health Research Centre (AHRC), Li Ka Shing Knowledge Institute of St. Michael's Hospital, Toronto, Ontario, Canada; p.bobos@mail.utoronto.ca

\section{ABSTRACT}

Objectives The objective of this survey was to investigate the barriers, facilitators, expectations and patient preferences regarding joint protection (JP) programmes in people with hand arthritis.

Design Cross-sectional survey.

Setting Tertiary clinic.

Participants Patients with hand arthritis: osteoarthritis, rheumatoid arthritis, psoriatic arthritis and other forms of arthritis.

Primary and secondary outcome measures This study used a survey among people with hand arthritis. Descriptive statistics and percentages were reported for all the data about the barriers, facilitators and preferences around JP.

Results A total of 192 patients consented to participate. Most of the patients (82\%) were unaware of JP. Factors that may act as barriers to participation and were regarded as 'a very big concern' were: cost of the programme (44\%), time of offering the programme (39\%), work commitments (36\%) and having a centre/clinic close to the house (28\%). Factors that may act as facilitators and rated as 'extremely helpful' were: research that shows that JP works (26\%) and having the centre/clinic close to the house (25\%). An online format for JP was the most preferred option (54\%). Half (46\%) preferred a timeframe of 1 hour, three times per week and $44 \%$ preferred a 2 hour programme, for three times per week.

Conclusions Awareness of the potential benefits of JP, and prior experience with JP programme were very low. Common potentially modifiable patient-reported barriers to participate in future JP interventions, included: cost, work commitments, distance from home to clinic and times that the intervention were provided. These barriers might be addressed with free and accessible forms of delivery of $\mathrm{JP}$, which may lead to better uptake and participation in JP programmes.

\section{INTRODUCTION}

Osteoarthritis (OA) is characterised as a degenerative joint disease that affects approximately 27 million adults in the USA and is one of the leading causes of disability. ${ }^{1}$ Osteoarthritis affects $60 \%$ to $70 \%$ of the population above the age of 65 years, and is likely
Strengths and limitations of this study

- The survey was adapted to people with hand arthritis from a validated questionnaire developed to assess the barriers, facilitators and preferences to exercise used in other clinical populations.

- A small sample of people with experience of joint protection prevented us from adequately exploring the perceptions of patients who had completed the programme.

- The survey was designed for English speakers with hand arthritis therefore, people speaking other languages were not represented.

to increase further in the future, due to the ageing population. ${ }^{23}$ The most common site of $\mathrm{OA}$ is the hand and it typically involves the interphalangeal (proximal and distal) and first carpometacarpal joints. ${ }^{4}$ In a clinical setting, pain is a major symptom among patients with hand $\mathrm{OA}$ as it contributes to a reduction in joint function. ${ }^{14}$ Currently there is no cure for hand OA, but goals of treatment include maximising long-term health-related quality of life, by controlling symptoms such as pain, prevention of structural damage and normalisation of function. ${ }^{5}$

Joint protection (JP) is a self-management strategy for patients living with arthritis to help preserve joint function and reduce pain. ${ }^{6} \mathrm{JP}$ involve training on 'safer movement patterns, the use of adaptive devices (eg, built up handles, hands free technologies) and behaviour modifications (eg, activities to avoid, pacing) during physical activity. ${ }^{6}$ However, JP can be implemented in many different ways, and patient preferences are rarely reported as being considered in programme design. There are many unknown barriers that may reduce participation in JP programmes, and these may be related to personal beliefs, preferences or 
circumstances. For example, patients may believe that JP will not slow joint damage, may not like engaging in groups or may have life/location issues that make it difficult to attend clinics. Identifying these barriers at group and individual levels may be a strategy to design and customise future JP to increase participation in JP programmes.

Considering preferences and customising JP may be critical to improving adherence. Prior reports suggest that adherence is a major concern. Previous systematic review and meta-analysis indicated that only 6 out of the 17 trials used strategies to maximise adherence for $\mathrm{JP}^{7}$ Although the evaluation of adherence from these trials was ranging from low-to-moderate adherence has not been properly studied in the published literature yet. The purpose of this cross-sectional survey is to investigate the barriers, facilitators, expectations and patient preferences regarding JP programmes in people with hand arthritis.

\section{METHODS}

\section{Patient and public involvement}

Patients or the public were not involved in the design, or conduct, or reporting, or dissemination plans of our research.

\section{Study design}

This study used a cross-sectional survey among people with hand arthritis that was open for response from March 2019 to February 2020.

\section{Inclusion criteria and exclusion criteria}

Participants were eligible to complete the anonymised survey if they were able and willing to provide informed consent, were between 18 to 85 years old, they have been diagnosed with hand arthritis and they could read and write English. Participants which have not been diagnosed with hand arthritis or they could not answer the survey questions, or they did not understand English were excluded from the study.

\section{Setting and recruitment}

Participants were recruited through advertisements in the main website of The Arthritis Society of Canada and from the Roth McFarlane Hand and Upper Limb Centre (HULC) at St. Joseph's Health Care Hospital in London, Ontario. Research assistants and research coordinators from HULC contacted people with hand arthritis who had previously expressed interest in participating in research. Also, an informative poster was setup at HULC patient waiting area providing details about the study. Two separate approaches were used for data collection: an online form to complete the survey and a paper-based version of the survey form at HULC clinical research laboratory.

\section{Data protection}

No participant identifying information was collected in this anonymised survey. Data were kept at the HULC clinical research laboratory where only authorised personnel have access, and all paper-based files were stored in a locked cabinet. Electronic files were stored in encrypted file and apart from the study investigators no other person had access to the electronic records.

\section{Survey}

The survey was adapted to people with hand arthritis based on previous experience of the study investigator (JCM) with JP, from a validated questionnaire initially developed to assess the barriers, facilitators and preferences to exercise for people with osteoporosis and for shoulder arthritis. ${ }^{89}$ The survey consisted of 31 questions with sections related to barriers, facilitators, expectations and patient preferences for JP programmes in people with hand arthritis. The survey questions are presented in the online supplemental web appendix.

\section{Data analysis}

\section{Quantitative}

Descriptive statistics and percentages were reported for all the data about the barriers, facilitators and preferences around JP programmes. In 2014 (Statistics, Canada), $16.5 \%$ of Canadians (around 4.8 million people) reported that they had been diagnosed with any form of arthritis by a health professional. The Ontario province represents the $18.5 \%$ of 4.8 million which is 888000 individuals with arthritis approximately. Sample size calculation was based on a population size of 888000 individuals, a confidence level of $95 \%$ and with $7 \%$ margin of error and it was determined that 196 individuals were needed to complete the survey. ${ }^{10}$ Data analyses were completed using Stata V.16.0.

\section{Qualitative}

Some of the survey questions (Questions 7, 8, 10, 11, 12, 13) were written responses. For these questions qualitative data analyses techniques were used. Data were analysed by response line to identify emerging codes. Relationships and similarities among codes were discussed leading to the formation of themes. Themes were particularly identified to provide new information to the quantitative responses, in an effort to better understand the barriers and facilitators to use of JP programmes. ${ }^{11-13}$

\section{RESULTS}

A total of 192 patients consented to participate and completed our survey. They provided information about JP barriers and facilitators regarding their possible prospective participation in a JP programme, the impact of JP programmes on domains of their everyday life and their preferred frequency of use of JP. Out of the 192 survey respondents, $92(50 \%)$ were diagnosed with rheumatoid arthritis (RA) in the hand, $38(21 \%)$ with hand OA, $29(16 \%)$ with psoriatic arthritis (PsA), $13(7 \%)$ had a diagnosis other than hand arthritis and $10(5 \%)$ reported none from the options provided. The majority of participants were aged between 34 to 54 years old representing the $53 \%$ of the sample of this survey. Thirteen $(n=13)$ 


\begin{tabular}{|c|c|c|}
\hline Variable & $\%$ & $\mathbf{n}$ \\
\hline \multicolumn{3}{|l|}{ Age (years) } \\
\hline $18-24$ & $3 \%$ & 5 \\
\hline $25-34$ & $11 \%$ & 19 \\
\hline $35-44$ & $26 \%$ & 45 \\
\hline $45-54$ & $26 \%$ & 45 \\
\hline $55-64$ & $23 \%$ & 39 \\
\hline $65-74$ & $7 \%$ & 12 \\
\hline $75-84$ & $1 \%$ & 2 \\
\hline Diagnosis (hand) & & 182 \\
\hline Osteoarthritis & $22 \%$ & 38 \\
\hline Rheumatoid arthritis & $51 \%$ & 92 \\
\hline Psoriatic arthritis & $16 \%$ & 29 \\
\hline Other form of arthritis & $7 \%$ & 13 \\
\hline None of the above & $5 \%$ & 10 \\
\hline \multicolumn{3}{|l|}{ Joint protection } \\
\hline $\begin{array}{l}\text { I am currently taking part in a joint } \\
\text { protection programme }\end{array}$ & $4 \%$ & 6 \\
\hline $\begin{array}{l}\text { I have previously taken part in a joint } \\
\text { protection programme }\end{array}$ & $5 \%$ & 7 \\
\hline $\begin{array}{l}\text { I have heard about joint protection but } \\
\text { have not taken part in a programme }\end{array}$ & $10 \%$ & 17 \\
\hline $\begin{array}{l}\text { I have not heard about any joint protection } \\
\text { programmes }\end{array}$ & $82 \%$ & 134 \\
\hline \multicolumn{3}{|l|}{ Setting } \\
\hline Inpatient - rehabilitation unit & $8 \%$ & 1 \\
\hline Inpatient - hospital & $8 \%$ & 1 \\
\hline Outpatient - hospital & $38 \%$ & 5 \\
\hline Home care & $8 \%$ & 1 \\
\hline A rehabilitation centre/clinic & $15 \%$ & 2 \\
\hline Family physician & $23 \%$ & 3 \\
\hline \multicolumn{3}{|l|}{ Joint protection provider } \\
\hline Family physician or specialist & $38 \%$ & 5 \\
\hline Occupational therapist & $46 \%$ & 6 \\
\hline Physiotherapist & $15 \%$ & 2 \\
\hline
\end{tabular}

people disqualified from the survey, because 3 of them were under 18 years old and 10 of them had arthritis in lower extremities and therefore, they were deemed ineligible to participate. The demographic description of the included sample is presented on table 1 .

\section{Awareness of joint protection programmes}

Regarding patients' awareness of JP programmes, from the 164 patients in total who had hand arthritis, most $(82 \%)$ had never heard about JP programmes before, $11 \%$ had heard about JP but had never taken part in such a programme. A small percentage of respondents (5\%) had previously taken part in a JP and only $4 \%$ were currently participating in a JP programme. Among the
Table 2 Examples provided of joint protection principles reported by patients that used them

Example 1 'Learnt how to do things safer for my hands, reenforced pacing'

Example 2 'Wearing thumb caps for working in the garden, wrist guards while using my hands. Splints for hands and feet'

Example 3 'I choose to use larger muscles and joints to aid me in completing day-to-day tasks, and I use splinting to reduce pain, weakness and fatigue'

Example 4 'I wore resting splints for 30 years. I have a key turner and a right-angled knife. I try to always use the largest joints. My taps and light switches are modified. I changed my cupboard handles. I use lightweight plates and an electric toothbrush'

13 participants who took part in JP, 5 people participated in a programme in an outpatient hospital department, 3 at a family's physician office, 2 in an inpatient unit, 2 in a rehabilitation centre and 1 home. The JP programme was provided most commonly by an occupational therapist $(46 \%)$, a family physician or specialist (38\%) and to a lesser extent by a physiotherapist (15\%) (table 1).

\section{Use, frequency and perceived impact of joint protection programmes on outcomes}

Out of 13 patients who participated in a JP programme, 5 of them continued using the principles of the programme at least once a week, 4 of them kept using them always, 1 participant applied them less than once a week while 3 of them did not use them at all. In table 2, 4 patients that participated in the joint protection provided examples what joint protection principles they used. Within this small subsample of 10 patients' experiences (figure 1), 8 patients reported 'no change' to 'very much better' in terms of impact on stiffness, pain, grip strength, hand function and swelling. Two patients reported feeling slightly worse to much worse in stiffness, pain, grips strength, hand function and swelling (figure 1).

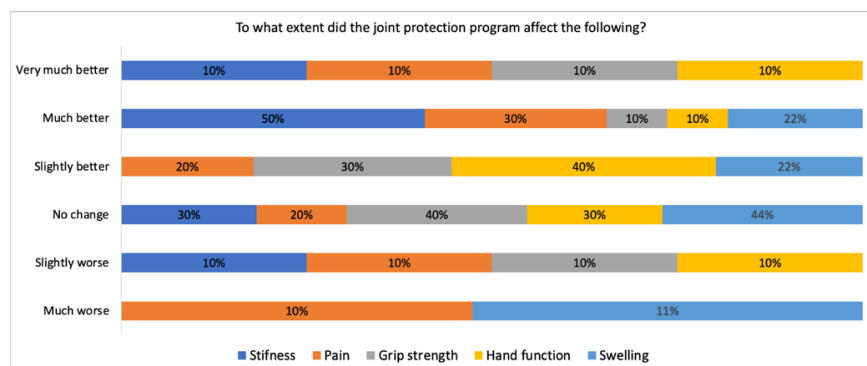

Figure 1 Individuals who took part into joint protection $(n=10)$ where asked to what extent did the joint protection (JP) affect stiffness, pain, grip strength, hand function and swelling. Only 2 out of 10 individuals that participated in JP experienced slightly worse to much worse outcomes. 


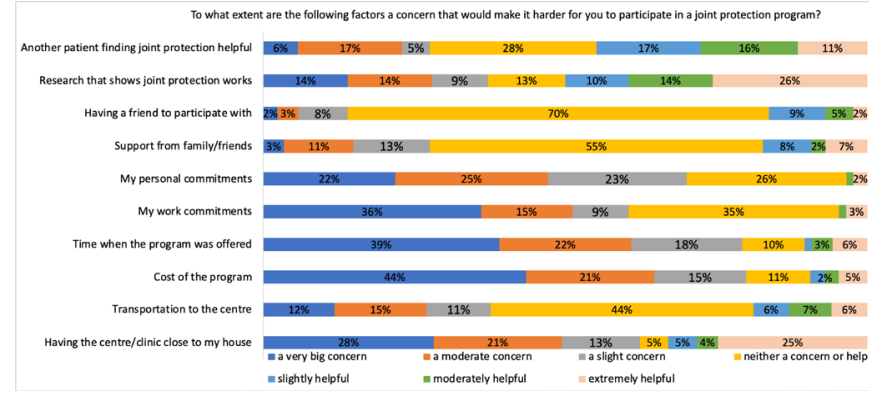

Figure 2 Factors perceived either as facilitators or barriers that may affect participation in a joint protection programme.

\section{Information and awareness of the existence of joint protection programmes}

The majority of the respondents have never heard about joint protection programmes until they undertook this survey, according to their comments in an open-ended question within the survey. None were informed about the existence of the joint protection programmes by a family physician or a local community centre. A small percentage of $14 \%$ were informed by a specialist about the existence of the JP programmes, $10 \%$ of them heard it from television, $5 \%$ by their therapist and $3 \%$ from family or friends.

\section{Factors affecting prospective participation in joint protection}

Factors reported by 87 participants that were reported as important barriers to participation in a future JP are described in figure 2. Factors that may act as barriers to participation and were regarded as 'a very big concern' included: cost of the programme (44\%), time of offering the programme $(39 \%)$, work commitments $(36 \%)$ and having a centre/clinic close to the house (28\%). Factors that may act as facilitators to participation and rated as 'extremely helpful' were: research that shows that joint protection works $(26 \%)$ and having the centre/clinic close to the house $(25 \%)$ ). All the barriers and facilitators that may affect participation are presented in figure 2.

\section{Qualitative data}

A total of 73 participants provided additional information in open-ended responses to describe their barriers and facilitators to engaging in a JP programme. Three major themes emerged: personal factors; environmental factors; and health factors. For the personal factors, common barriers were energy, other personal or work commitments and fear of further injury. Environmental factors included having a centre close to the house, transportation, cost of the programme, building accessibilities and social support from family or friends to participate with. Health factors included comorbidities associated with the disease, complications related to the disease, flare ups and depression. For example, one participant noted that arthritis-related health issues limited participation: RA said '[permanent] RA voice loss, [permanent] RA lung damage', and another patient mentioned 'flare ups'.
Facilitators mentioned in open-ended responses included: having the centre/clinic close to my house, transportation to the centre where programme is provided, cost of the programme, time when the programme was offered, my work commitments, my personal commitments, support from family/friends, having a friend to participate with, research that shows joint protect works and another patient finding joint protection helpful. A number of the barriers mentioned in open-ended responses related to health factors not specifically identified on the survey: flare ups, fear of further injury and comorbid conditions were not listed as potential barriers in the survey.

\section{Preference on method of delivery of joint protection}

An online format for JP was the most preferred option representing slightly over half of the respondents (54\%). Among the remaining respondents there were preferences for at home (20\%), clinic (17\%), videos $(6 \%)$ and printed material $(2 \%)$. Patient were open to a variety of health providers for JP programmes, and stated preference for occupational therapists (22\%), physiotherapists $(20 \%)$, family physician or specialists such as rheumatologists $(19 \%)$, hand therapists $(17 \%)$, other patients with arthritis (13\%) and kinesiologists with the other choices comprising $2 \%$.

\section{Preference of frequency of joint protection}

Participants reported their top preference in terms of frequency and their possible prospective participation in a JP. Half of them (46\%) preferred a timeframe of 1 hour, three times per week for 10 weeks and $44 \%$ preferred a 2-hour, three times a week for 5 weeks programme.

\section{Usefulness of joint protection components}

Patient preferences for content in JP suggest that information about joint loading, reduction of joint stress, feedback on correctness and carefulness in tasks, information about pacing activities, advice from health professionals or other patients and demonstration of how to do things in ways that minimise effort and maximise efficiency, a JP programme were considered as moderately-to-extremely useful (figure 3). Respondents indicated that the following information would be moderately or extremely useful: activity pacing and how joint positions affect joint loading, ways to reduce joint loading and feedback on task performance. They indicated preference as 'moderately' or 'extremely useful' the following approaches: advice from health professionals, demonstrations/feedback on task performance and advice from other patients (figure 3).

\section{Perceived importance of joint protection programmes}

Patients rated the following potential outcomes of JP as 'extremely important': pain reduction (92\%), joint deformity prevention (83\%), hand function (82\%) and grip strength $(75 \%)$. On average 84 out of 192 of patients reported how often they use one or more of the following rehabilitation modalities such as heat, cold, 


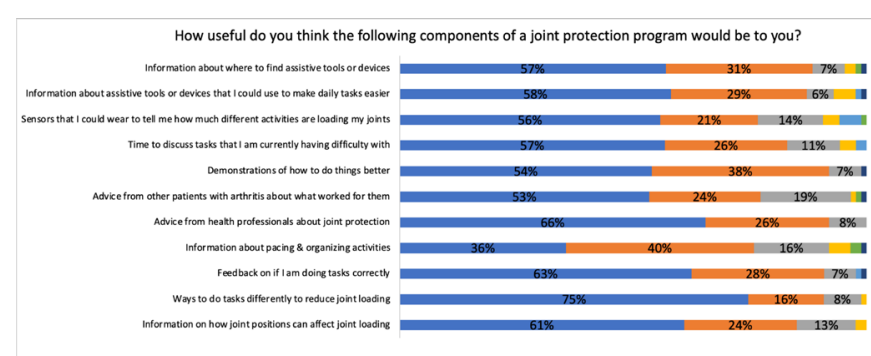

Figure 3 Participants were asked to rate the following components of joint protection from 'extremely useful' to 'extremely useless'.

exercise, joint protection, splints and modified equipment (figure 4). Modalities such as heat, exercise and splints were reported that were used 'very frequently' by $15 \%$ of the respondents. Heat (32\%), exercise $(25 \%)$ and cold modalities (19\%) were used as 'frequently' by the participants. On the other hand, modalities such TENS/ electrical devices $(68 \%)$, splints $(46 \%)$, joint protection $(48 \%)$ and modified equipment $(43 \%)$ were never used by the respondents (figure 4).

\section{DISCUSSION}

This study found that very few patients with arthritis were aware of or had participated in a JP programme, yet slightly more than half favoured a JP programme which could be offered three times per week at 1 to 2 hours of engagement in an online format. This suggests a profound need for better accessibility to JP programmes for people with arthritis as a component of their overall self-management strategy.

It is also clear one single method of delivery is unlikely to meet all needs since variation in preferences was clear. An online format for JP was the most preferred option representing slightly over half of the respondents (54\%). Other preferred options were JP programmes that could be completed at home $(21 \%)$ or at a clinic $(16 \%)$. Our findings need to be tempered by two considerations. First, some of the other preferred options overlap, for example, preferences like 'at home' or 'videos' could include virtual components. Second, since the majority of the respondents $(82 \%)$ were unaware of JP and were rarely using it, their preferences were based on a priori assumptions not on experience with such programmes.

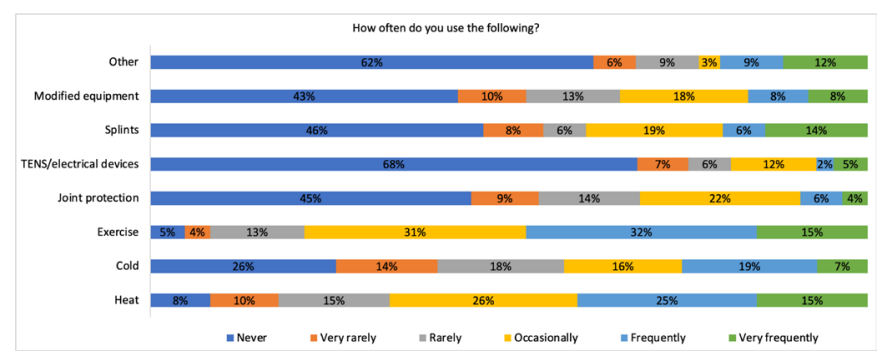

Figure 4 Individuals were asked how often they used the following modalities to manage their symptoms.
However, preferences prior to participation are important since this is the time when patients make decisions about participation.

It was remarkable that so few respondents had participated in JP programme, given that there is systematic review evidence demonstrating the effectiveness of these programmes both for patients with RA and OA. ${ }^{14}$ The included trials in this meta-analysis were of low methodological quality however, the effects of JP on function outcomes for people with RA in the hand were beneficial. In the few people who have used JP in our survey the experiences were mostly positive in terms of perceived benefit in symptom control and very limited perceived harm. Lack of awareness of JP programme was greater than anticipated and may reflect a lack of access to programmes, a lack of awareness in clinicians who should be recommending JP programme or a lack of interest in participating. Self-management strategies are important for patients with arthritis since it is a chronic disease. In fact, many of the patients in this survey were participating in some aspect of self-management. JP effectiveness has been supported by systematic reviews. ${ }^{6} 714$ Therefore, our finding that only 10 had participated in suggests that there is a substantial gap in awareness, delivery and accessibility of these programmes.

Respondents identified several challenges to participate in JP programmes. This suggests that flexibility in how/when programmes are offered is a critical factor in programme planning. Patients placed high importance on participation in JP if research findings show that this programme actually works. Pain reduction outcomes, joint deformity prevention, hand function and grip strength outcomes were all judged as being 'extremely important' by the patients. Since all of these outcomes are important to patients it would be that adherence to JP could be improved by clear explanations of how JP can benefit each of these outcomes both a conceptual level and with the current research evidence that suggests benefits to these outcomes.

The level of participation preferred by potential participants in JP in this study equates to 3 to 6 hours per week, and is similar to that performed in clinical trials of JP in patients with OA and RA in the hand. ${ }^{15-17}$ Half of the respondents ranked the online format as the first choice over all the other methods of delivery of JP with home programme being the second most preferred choice. This finding is consistent with a recent study where patients with RA reported that a home version of a hand exercise programme, which was held online was very useful and authors suggested that this might contribute to better adherence in long-term. ${ }^{18}$ Data from an randomised controlled trial of behavioural and hand exercises interventions in women with arthritis also suggested home programmes may increase participation. ${ }^{19}$ The recent pandemic has forced many countries to re-evaluate how care is delivered to maintain social distancing or self-isolation. ${ }^{20}$ The pandemic has heightened the lack of access to care for people with arthritis as this care is 
considered non-essential. At the same time, it has opened up the pathway for innovation and acceptance of alternative delivery models that provide remote accessibility. Since our data was collected pre-pandemic, we can only assume that preference for online programmes would have increased. While the efficacy of JP interventions with hand exercises has been evaluated it is difficult for patients with hand arthritis to have confidence that an online or remote intervention is equally effective method to control their symptoms without being tested in future trials. ${ }^{7}$ This underlines the importance of trials and posttrial implementation studies to provide more definitive evidence on the impact of virtual JP programmes.

The third most preferred choice of JP delivery was at the clinic. Our previous studies of information access preferences in patients with fibromyalgia ${ }^{21} 22$ indicated that face-to-face interaction with healthcare providers was the most preferred way of getting information and it is likely that this is the positive aspect for attending a clinical site. Previous review has indicated that patient-centred interaction styles related to the provision of emotional support and allowing patient involvement in the consultation process may enhance the therapeutic alliance between clinician and patient. ${ }^{23}$ Effective communication between the clinician and the patient relies on verbal but also on non-verbal factors, and this can usually be achieved in an in-person encounter. ${ }^{24}$ The value of face-to-face interaction may mean that online interventions although theoretically more accessible, may not instigate the same level of engagement or adherence.

Another key finding of this study is that the cost of the JP programme, working commitments, the time that JP is offered as well as the distance from home to clinic were regarded as the main barriers and could substantially decrease participation in JP. Financial burden and time have been previously described for patients with RA as a perceived barrier. ${ }^{25}{ }^{26}$ From the qualitative analysis barriers associated with health factors were novel, and not well captured in the survey.

Respondents identified a variety of perceived important outcomes with pain reduction, joint deformity prevention and hand function being the main predominant ones. This is consistent with the core set outcome measures that has been proposed from OMERACT - Osteoarthritis Research Society International (OMERACT-OARSI) set of responder criteria. ${ }^{27}$ Clinical outcomes for hand OA such as aesthetic damage in the joints and measured performance and function have been recommended by patients. ${ }^{28}{ }^{29}$ Based on patients' perceived benefit, JP programmes appeared to have neutral-to-positive impact on stiffness, pain, grip strength, hand function and swelling. While this is consistent with a recent metaanalysis ${ }^{714}$ there was a very low number of respondents that used JP in our sample.

Our study has several limitations that need to be taken into account when interpreting our study findings. Since the survey was designed for English speakers with hand arthritis, people speaking other languages were not represented. Potentially cultural, language and health system issues could affect preferences. The survey responses were recorded online, and patients did not have access to electronic devices could not participate in the survey. However, we offered a paper version survey for individuals as an alternative. Finally, the small sample of people with experience of JP prevented us from adequately exploring the perceptions of patients who had completed the training.

\section{Future research and clinical implications}

While this survey is a first step to understand what factors affect participation rates in people who are candidates for JP, studies that collect patient perceptions of draft programmes in a co-design process are needed to create a patient-preference based JP programme. It is possible that preferences will change or become more specific through a co-design process. A future trial to compare alternative delivery models is highly needed. Our survey identified principles of JP that the patients perceived as extremely important and it is unclear if these components were present in the published efficacy trials, since these studies have inadequate reporting. ${ }^{7}$ Adherence to guidelines such as Template for Intervention Description and Replication (TIDieR) and presentation of theoretical assumptions for the content of programmes would improve fidelity across studies and in converting current JP programmes to online formats. ${ }^{30}$ One of the most important findings of our work is the lack of awareness about, and participation in JP in a sample of people for who current best evidence suggest this would be effective. Education of healthcare professionals about this option and improved accessibility to programmes is indicated to improve clinical outcomes.

\section{CONCLUSIONS}

Awareness of the potential benefits of JP, and prior experience with JP programme were very low. Common potentially modifiable patient-reported barriers to participate in future JP interventions, included: cost, work commitments, distance from home to clinic and times that the JP intervention were provided. These barriers might be addressed with free and accessible forms of delivery of JP, which may lead to better uptake and participation in JP.

\section{Author affiliations}

${ }^{1}$ Health and Rehabilitation Sciences, Western University, London, Ontario, Canada ${ }^{2}$ Dalla Lana School of Public Health, Institute of Health Policy Management and Evaluation, University of Toronto, Toronto, Ontario, Canada

${ }^{3}$ Applied Health Research Centre (AHRC), Li Ka Shing Knowledge Institute of St. Michael's Hospital, Toronto, Ontario, Canada

${ }^{4}$ School of Rehabilitation Science, McMaster University, Hamilton, Ontario, Canada

${ }^{5}$ Physical Therapy, Western University, London, Ontario, Canada

${ }^{6}$ Roth McFarlane Hand and Upper Limb Centre, Western University, London, Ontario, Canada

${ }^{7}$ Hygiene, Epidemiology and Medical Statistics, National and Kapodistrian University of Athens, Athens, Attica, Greece

${ }^{8}$ Mechanical and Materials Engineering, Western University, London, Ontario, Canada 


\section{Twitter Pavlos Bobos @pavlosbob}

Acknowledgements Pavlos Bobos was supported by the Canadian Institutes of Health Research (CIHR) Doctoral Award and the Arthritis Society Postdoctoral Fellowship Award. Christina Ziebart was supported by the CIHR Doctoral Award. Joy C MacDermid was supported by a CIHR Chair in Gender, Work and Health and Dr James Roth Research Chair in Musculoskeletal Measurement and Knowledge Translation.

Contributors PB contributed significantly to conception and design of the study, data extraction, interpretation of data and drafting of the manuscript. PB and EB contributed to data management. CZ and EB were involved in interpretation of data and drafting. EL, LF and RG were involved in acquiring operating funds, project supervision, data interpretation and drafting. JM was also involved in the conception and design of the study, drafting and revised the manuscript for important intellectual content. All authors have given their final approval on the manuscript to be published.

Funding This study was supported by the Canadian Institutes of Health Research (CIHR) with funding reference number (FRN: 201710GSD-402354-282879) and by an operating grant from the Arthritis Society of Canada.

Competing interests None declared.

Patient consent for publication Not required.

Ethics approval Ethical approval was granted by Hamilton Research Ethics Board (HiREB) at McMaster University, Hamilton, Canada (Project Number: 3727). Patients were asked to provide consent to proceed and complete the survey questions.

Provenance and peer review Not commissioned; externally peer reviewed.

Data availability statement No data are available. Data sharing is not allowed from our Institutional Research Ethics Board.

Supplemental material This content has been supplied by the author(s). It has not been vetted by BMJ Publishing Group Limited (BMJ) and may not have been peer-reviewed. Any opinions or recommendations discussed are solely those of the author(s) and are not endorsed by BMJ. BMJ disclaims all liability and responsibility arising from any reliance placed on the content. Where the content includes any translated material, BMJ does not warrant the accuracy and reliability of the translations (including but not limited to local regulations, clinical guidelines, terminology, drug names and drug dosages), and is not responsible for any error and/or omissions arising from translation and adaptation or otherwise.

Open access This is an open access article distributed in accordance with the Creative Commons Attribution Non Commercial (CC BY-NC 4.0) license, which permits others to distribute, remix, adapt, build upon this work non-commercially, and license their derivative works on different terms, provided the original work is properly cited, appropriate credit is given, any changes made indicated, and the use is non-commercial. See: http://creativecommons.org/licenses/by-nc/4.0/.

ORCID iDs

Pavlos Bobos http://orcid.org/0000-0002-5098-4840

Christina Ziebart http://orcid.org/0000-0002-3667-4133

\section{REFERENCES}

1 Dibonaventura Mdacosta, Gupta S, McDonald M, et al. Evaluating the health and economic impact of osteoarthritis pain in the workforce: results from the National health and wellness survey. BMC Musculoskelet Disord 2011;12:83.

2 Dahaghin S, Bierma-Zeinstra SMA, Ginai AZ, et al. Prevalence and pattern of radiographic hand osteoarthritis and association with pain and disability (the Rotterdam study). Ann Rheum Dis 2005;64:682-7.

3 Stoffer-Marx MA, Klinger M, Luschin S, et al. Functional consultation and exercises improve grip strength in osteoarthritis of the hand - a randomised controlled trial. Arthritis Res Ther 2018;20:253.

4 Ceceli E, Gül S, Borman P, et al. Hand function in female patients with hand osteoarthritis: relation with radiological progression. Hand 2012;7:335-40.

5 Kloppenburg M, Kroon FP, Blanco FJ. Update of the EULAR recommendations for the management of hand osteoarthritis. Ann Rheum Dis 2018;2019:16.

6 Bobos P, Nazari G, Lalone EA, et al. A scoping review of joint protection programs for people with hand arthritis. Open Orthop $J$ 2018;12:500-13.
7 Bobos P, Nazari G, Szekeres M, et al. The effectiveness of jointprotection programs on pain, hand function, and grip strength levels in patients with hand arthritis: a systematic review and meta-analysis. $J$ Hand Ther 2019:32:194-211.

8 Rodrigues IB, Adachi JD, Beattie KA, et al. Development and validation of a new tool to measure the facilitators, barriers and preferences to exercise in people with osteoporosis. BMC Musculoskelet Disord 2017;18:540.

9 Rodrigues IB, Adachi JD, Beattie KA, et al. Determining known-group validity and test-retest reliability in the PEQ (personalized exercise questionnaire). BMC Musculoskelet Disord 2019;20:373.

10 Bartlett JE, Kotrlik J, Higgins C. Organizational research: determining appropriate sample size in survey research appropriate sample size in survey research. Inform Technol Learn Perform J 2001;19:43.

11 Sandelowski M. Whatever happened to qualitative description? Res Nurs Health 2000;23:334-40.

12 Sandelowski M. What's in a name? Qualitative description revisited. Res Nurs Health 2010;33:77-84.

13 Sandelowski MJ. Justifying qualitative research. Res Nurs Health 2008;31:193-5

14 Bobos P, MacDermid JC, Nazari G, et al. Joint protection programmes for people with osteoarthritis and rheumatoid arthritis of the hand: an overview of systematic reviews. Physiotherapy Canada 2020:e20190037

15 Williams MA, Williamson EM, Heine PJ, et al. Strengthening and stretching for rheumatoid arthritis of the hand (Sarah). A randomised controlled trial and economic evaluation. Health Technol Assess 2015;19:1-222.

16 Dziedzic K, Nicholls E, Hill S, et al. Self-management approaches for osteoarthritis in the hand: a $2 \times 2$ factorial randomised trial. Ann Rheum Dis 2015;74:108-18.

17 Hammond A, Lincoln N. The effect of a joint protection education programme for people with rheumatoid arthritis. Clin Rehabil 1999;13:392-400.

18 Srikesavan C, Williamson E, Cranston T, et al. An online hand exercise intervention for adults with rheumatoid arthritis (mySARAH): design, development, and usability testing. J Med Internet Res 2018;20:e10457.

19 Hennig T, Hæhre L, Hornburg VT, et al. Effect of home-based hand exercises in women with hand osteoarthritis: a randomised controlled trial. Ann Rheum Dis 2015;74:1501-8.

20 Jüni $\mathrm{P}$, Rothenbühler $\mathrm{M}$, Bobos $\mathrm{P}$, et al. Impact of climate and public health interventions on the COVID-19 pandemic: a prospective cohort study. CMAJ 2020;192:E566-73.

21 Daraz L, MacDermid JC, Shaw L, et al. Experiences of women living with fibromyalgia: an exploratory study of their information needs and preferences. Rheumatol Rep 2011;3:15.

22 Daraz L, Macdermid JC, Wilkins S, et al. The quality of websites addressing fibromyalgia: an assessment of quality and readability using standardised tools. BMJ Open 2011;1:e000152.

23 Pinto RZ, Ferreira ML, Oliveira VC, et al. Patient-centred communication is associated with positive therapeutic alliance: a systematic review. J Physiother 2012;58:77-87.

24 Roberts L, Bucksey SJ. Communicating with patients: what happens in practice? Phys Ther 2007;87:586-94

25 Owensby JK, Chen L, O’Beirne R, et al. Patient and rheumatologist perspectives regarding challenges to achieving optimal disease control in rheumatoid arthritis. Arthritis Care Res 2020;72:933-41.

26 Veldhuijzen van Zanten JJCS, Rouse PC, Hale ED, et al. Perceived barriers, facilitators and benefits for regular physical activity and exercise in patients with rheumatoid arthritis: a review of the literature. Sports Med 2015;45:1401-12.

27 Pham T, Van Der Heijde D, Lassere M, et al. Outcome variables for osteoarthritis clinical trials: the OMERACT-OARSI set of Responder criteria. J Rheumatol 2003;30:1648.

28 Stamm T, Machold K, Aletaha D, et al. Klinische Ergebnismessgrößen bei Arthrose Der Hand- und Fingergelenke AUS Der Perspektive Der Patienten. Z Rheumatol 2006;65:139-43.

29 Bobos P, MacDermid JC, Boutsikari EC, et al. Evaluation of the content validity index of the Australian/Canadian osteoarthritis hand index, the patient-rated wrist/hand evaluation and the thumb disability exam in people with hand arthritis. Health Qual Life Outcomes 2020;18:302.

30 Hoffmann TC, Glasziou PP, Boutron I, et al. Better reporting of interventions: template for intervention description and replication (TIDieR) checklist and guide. BMJ 2014;348:g1687. 